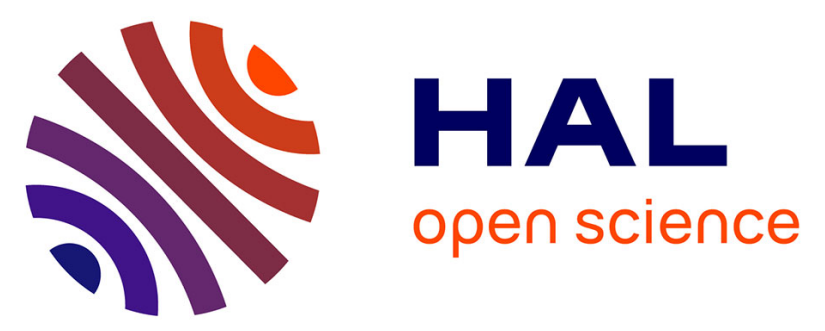

\title{
Investigating compatibility between TPU and bitumen SARA fractions by means of Hansen solubility parameters and interfacial tension measurements
}

Raïssa Gallu, Françoise Méchin, Florent Dalmas, Jean-François Gerard, Rémi Perrin, Frédéric Loup

\section{To cite this version:}

Raïssa Gallu, Françoise Méchin, Florent Dalmas, Jean-François Gerard, Rémi Perrin, et al.. Investigating compatibility between TPU and bitumen SARA fractions by means of Hansen solubility parameters and interfacial tension measurements. Construction and Building Materials, 2021, 289, pp.123151. 10.1016/j.conbuildmat.2021.123151 . hal-03195768

\section{HAL Id: hal-03195768 https://hal.science/hal-03195768}

Submitted on 12 Apr 2021

HAL is a multi-disciplinary open access archive for the deposit and dissemination of scientific research documents, whether they are published or not. The documents may come from teaching and research institutions in France or abroad, or from public or private research centers.
L'archive ouverte pluridisciplinaire HAL, est destinée au dépôt et à la diffusion de documents scientifiques de niveau recherche, publiés ou non, émanant des établissements d'enseignement et de recherche français ou étrangers, des laboratoires publics ou privés. 


\section{Investigating compatibility between TPU and bitumen SARA fractions by means of Hansen}

Solubility Parameters and interfacial tension

\section{measurements.}

Raïssa Gallu ${ }^{1,2 *}$, Françoise Méchin $^{l}$, Florent Dalmas ${ }^{2 *}$, Jean-François Gérard $^{1}$, Rémi Perrin $^{3}$, Frédéric Loup ${ }^{4}$

${ }^{1}$ Univ Lyon, INSA Lyon, CNRS, IMP, UMR 5223, F-69621, Villeurbanne, France.

${ }^{2}$ Univ Lyon, INSA Lyon, CNRS, MATEIS, UMR 5510, F-69621, Villeurbanne, France.

${ }^{3}$ Soprema Co., 14 rue de Saint Nazaire, 67100 Strasbourg, France.

${ }^{4}$ Eiffage Infrastructure Co., Corbas, France.

Keywords. polymer-modified bitumen; thermoplastic polyurethane, Hansen solubility parameters, interfacial tension.

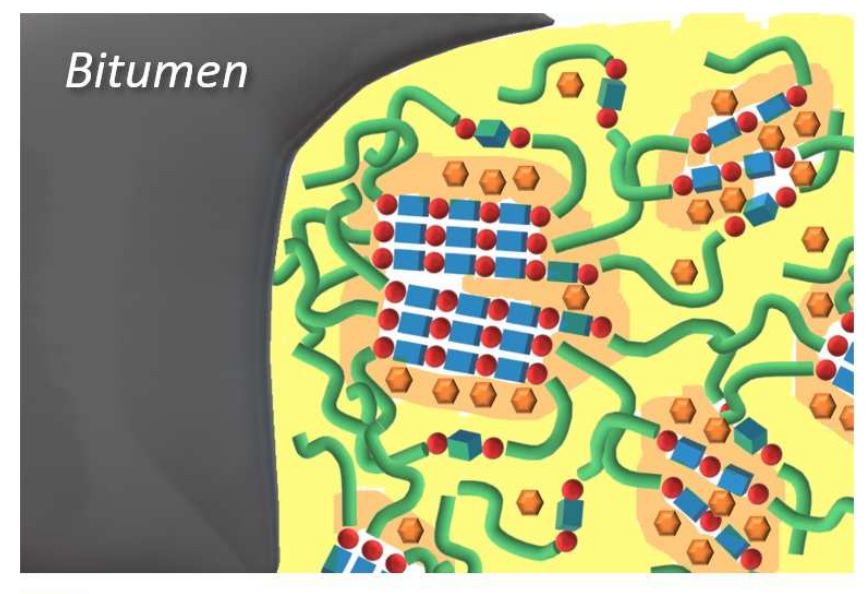

Resins

[0 Hard segment

Aromatics 2 Soft segment 


\begin{abstract}
.
Hansen solubility parameters (HSP) and model oils were used to predict the affinity of each block of the TPU (thermoplastic polyurethanes) with the SARA fractions (Saturates, Aromatics, Resins, Asphaltenes) of bitumen, revealing the preferential compatibility of the bitumen with the soft block of the TPU. More specifically, aromatics are highly compatible with the soft block while resins are compatible with soft and hard blocks of the TPU. Companion SAXS analysis highlighted that the microstructure of TPU is however maintained with semicrystalline hard nanodomains dispersed in a soft matrix with its amorphous part being swollen by resins. Interfacial tension measured by drop deformation retraction method (DDR) highlighted the compatibilizing role of resins as a lower interfacial tension value was measured at high resin content. In turn, different mechanical properties of TPU-modified bitumens were obtained when changing their composition. With similar morphologies for the blends (i.e. continuous TPU phase swollen with the same ratio), a decrease in rubbery storage modulus and flowing temperature was observed as the amount of resins increases.
\end{abstract}

\title{
1. INTRODUCTION.
}

Due to the complex composition of bitumen-polymer blends and the constant need to manufacture high performance waterproof binders, e.g. for road pavements or roofing applications, tailoring the polymer-bitumen compatibility in such blends is a key issue. Bitumen is certainly at the origin of this complexity, because of its internal composition made of a continuum of molecules of varying polarities, i.e. interactions with polymers. Indeed, several works have shown that compatibility in bitumen-polymer blends depends on bitumen 
composition expressed as the SARA fractions (Saturates, Aromatics, Resins, Asphaltenes)[1,2], polymer nature[3-5] and architecture[6].

Compatibility mechanisms have been the subject of numerous works in recent decades to establish relationships with the properties of formulated polymer-bitumen blends. Compatibility in blends usually involves thermodynamics approaches such as the FloryHuggins theory, dealing with the free energy $\Delta G_{M}$, the enthalpy $\Delta H_{M}$ and the entropy $\Delta S_{M}$, of mixing as expressed in the following equation:

$$
\Delta G_{M}=\Delta H_{M}-T \Delta S_{M}
$$

Compatibility between blend components implies a negative free energy of mixing. From Flory-Huggins theory, phases are considered for binary systems which display miscibility areas, delimited by the binodal and the spinodal curves. Two-phase diagrams are mainly described in literature which are related to, i/ an upper critical solution temperature (USCT) behavior associated with blends that segregate upon cooling, ii/ and a lower critical solution temperature (LCST) behavior for blends that segregate upon heating. Polymer combinations usually show a LCST behavior, as for block copolymers[7,8], but USCT behavior was also reported in the literature in some cases[9,10]. In the case of bitumen-polymer blends with a linear styrene-co-butadiene-co-styrene (SBS) block copolymer with a styrene:butadiene ratio 30:70, authors have reported that the thermodynamic equilibrium depends on several parameters such as SBS content, molar mass, or temperature. For blends based on 3, 6 and $10 \mathrm{wt} \%$ SBS, the LCST-type phase diagram evidences a miscibility window at low polymer content, with phase separation occurring at high temperature for blends having a SBS content 
higher than $6 \mathrm{wt} \%$. In addition, the phase separation occurs at different temperatures for the blends based on 6 and $10 \mathrm{wt} \%$ of SBS as well as differences in the phase composition[11]. Another work considering a mixture of triblock SBS and diblock SB copolymers (wt. ratio 86:14) with $33 \%$ of polystyrene, reported a UCST behavior with a critical solubility point at $200^{\circ} \mathrm{C}$ for $20 \mathrm{vol} \%$ of SBS in the bitumen[12]. Ho et al.[13] have shown, by considering a ternary phase diagram and using transmission electron microscopy, that it was possible to predict both macrophase separation from asphaltenes to SEBS (poly(styrene-b-(ethylene-cobutylene)-b-styrene)) wt. ratio and the microstructure of the SEBS-rich domains from the maltenes' concentration in SEBS-modified bitumen.

Based on thermodynamics concepts, solubility parameters turned out to be powerful data to predict compatibility between different chemical components. In the 1980 s, many works reported that polymers leading to compatible blends with bitumen should show Hildebrand solubility parameters taking into account all types of interactions, $\delta_{T O T}$, in the range from 16.6 to $17.6 \mathrm{MPa}^{1 / 2}$ whereas polymers showing higher solubility parameters lead to heterogeneous blends[14]. Polymers with such suitable solubility parameters include natural rubber, polyisoprene, polybutadiene, or styrene-butadiene rubbers.

Recently, the use of Hansen solubility parameters has shown relevant results when dealing with compatibility, even for block copolymers[15]. Hansen solubility parameters[16] distinguish three components, namely the dispersive $\delta_{D}$, polar $\delta_{P}$ and hydrogen bond $\delta_{H}$ components so that the total solubility can be additively decomposed as follow: 


$$
\delta_{T O T}^{2}=\delta_{D}^{2}+\delta_{P}^{2}+\delta_{H}^{2}
$$

These parameters allow to represent the solubility range of a compound by a sphere in a three dimension (3D) space with $\left(\delta_{D}, \delta_{P}, \delta_{H}\right)$ axes. Redelius[17] was the first author to report 3D solubility diagrams of bitumen and its fractions from solubilization in various solvents. With this approach, he studied the compatibility of bitumen with some polymers, such as polyether sulfone, polyethylene sulfide, or SBS. Polyether sulfone was found to be incompatible with bitumen, i.e. displaying a negligible overlap of their solubility spheres, whereas polyethylene sulfide showed good compatibility. In the case of SBS, an incomplete overlap was found, associated to a partial compatibility of this polymer with bitumen that is explained by the existence of two blocks having different chemical natures, i.e. polybutadiene and polystyrene. Recently, based on Redelius' work, Zhu et al.[18] reported that the use of solubility parameters considering both the distance between solubility sphere centers and the degree of overlapping of the solubility spheres was appropriate to accurately characterize the interactions taking place in bitumen-polymer blends. These authors also showed that it was possible to properly understand the storage stability and morphology in bitumen-polymer systems by associating solubility theory to the free energy of the blends. Another study on SBS-modified bitumens reported that the compatibility could be predicted either from considering the overall solubility parameter or the dispersive component as SBS is a nonpolar polymer $\left(\delta_{\mathrm{TOT}}=17.29 \mathrm{MPa}^{1 / 2}\right)$, whereas poor affinity could be expected with highly 
polar bitumens[19]. The use of Hansen solubility parameters was also associated to turbidimetric titration to describe compatibility between aged and non-aged bituminous binders[20]. The authors showed that aged bituminous binders display higher polar interactions due to the increase in asphaltenes content. Other works have reported the use of Hansen solubility parameters to predict compatibility in polymer blends[21] and polyol blends[22]' [23].

The compatibility in polymer blends can also be quantified from interfacial tension measurements. Literature describes several methods, such as pendant drop, Neumann triangle, imbedded fiber, breaking thread and rheological method[24-26]. However, these methods either require long equilibration times, i.e. thermally stable polymers, or have low accuracy. Rheological analyses are easier but are not direct due to the fact that they proceed from models and the knowledge of the morphology of the blends. Another method named drop deformation retraction (DDR) $[27,28]$ provides very low process times and accurate data especially for low values of interfacial tension.

Unlike polymer blends, interfacial tension measurements in bitumen-polymer blends is less common due to the complexity of the blends. Only a few studies deal with interfacial tension measurements in polymer-bitumen blends. The first ones were reported by Lesueur et al.[29] on SBS-modified bitumen from rheological analysis combined with the Palierne[30] emulsion model. The authors reported interfacial tension values from $10^{-6}$ to $10^{-5} \mathrm{~N} \cdot \mathrm{m}^{-1}$ at $120^{\circ}$ C. Recently, Roman and Garcia-Morales reported a value of 
$(1.75 \pm 0.26) 10^{-6} \mathrm{~N} \cdot \mathrm{m}^{-1}$ for a low density polyethylene-modified bitumen using drop deformation retraction method[31].

In a previous study, we have shown the interest of thermoplastic polyurethane (TPU) as a new polymer additive in polymer-modified bitumen[32]. TPU is basically composed of three components: a polyol, a diisocyanate, and a chain extender (low molar mass diol)[3335]. The reaction of the diisocyanate with the polyol leads to the formation of soft segments, denoted SS and having a glass transition temperature (Tg) lower than room temperature, while the reaction of the diisocyanate with the short diol leads to the formation of hard segments having a Tg above room temperature and potential crystallinity. As for SBS, TPU usually display a nanoscale morphology with two phases: a hard segment-rich dispersed nanophase (either amorphous or semi-crystalline) and a soft segment-rich continuous phase. We have shown that changing the TPU composition, i.e. hard segment content, led to the modification of the compatibility between TPU and bitumen, resulting in a decrease of the polymer swelling within the bitumen as the hard segment content increased. Macroscopically, such modification has, as expected, a strong impact on the viscoelastic behavior of the blend. It is well documented that asphaltenes are not involved in the compatibilization mechanism of conventional polymer additives in a bitumen[13]. In fact, as the formulation leads to a biphasic material, where the maltenes swell the polymer, the asphaltenes remain apart[32]. This behavior results from the difference of solubility parameters between the polymer and bitumen fractions which leads to destabilize the bitumen because of the swelling of the polymers by the low fractions and to the precipitation of the asphaltenes[17]. 
To go further, this study aims to more specifically describe the compatibility mechanism in bitumen modified with TPU. To this end, the study will focus on the interactions of the SARA fractions of bitumen and the TPU hard and soft blocks in view to better understand the mechanical properties of the resulting blends. To do so, the solubility parameters of bitumen are measured and compared with the previously reported solubility parameters of the TPU [15]. Then, model oils for the different fractions of bitumen are considered and their solubility parameters measured. The microstructure of model blends prepared from TPU and oils is investigated by X-ray scattering. Finally, bitumen-TPU interfacial tensions are measured as a function of bitumen composition and relationships between compatibility and rheological properties are discussed.

\section{EXPERIMENTAL SECTION}

\subsection{Materials.}

The SARA composition of the three bitumen and two model oils used to make the blends are reported in Table 1. A colophony resin supplied by Sigma Aldrich was used as a model for the resin $(\mathrm{R})$ fractions. A thermoplastic polyurethane from Soprema Co., synthesized by reactive extrusion from a polyester polyol based on fatty acid named Radia 7285, 4,4'methylene bis(phenyl isocyanate) (MDI), and 1,4-butanediol (BDO) as chain extender was used as the reference polymer for modification. This polymer named TPU13 contains $13 \mathrm{wt} \%$ MDI-BDO hard segments. 
Table 1. Composition of bitumen and model oils expressed in SARA fractions

\begin{tabular}{lccccc}
\hline Sample & $\begin{array}{c}\text { Saturates } \\
(\mathrm{wt} \%)\end{array}$ & $\begin{array}{c}\text { Aromatics } \\
(\mathrm{wt} \%)\end{array}$ & $\begin{array}{c}\text { Resins } \\
(\mathrm{wt} \%)\end{array}$ & $\begin{array}{c}\text { Asphaltenes } \\
(\mathrm{wt} \%)\end{array}$ & grade \\
\hline Bitumen A (BA) & 10.4 & 55.1 & 23.8 & 10.7 & $50 / 70$ \\
Bitumen B (BB) & 11.9 & 59.5 & 17.6 & 10.9 & $70 / 100$ \\
Bitumen C (BC) & 9.8 & 62.0 & 15.5 & 12.7 & $160 / 220$ \\
Naphthenic oil (N) & 11.7 & 80.5 & 7.8 & 0 & - \\
Paraffinic oil (P) & 66.4 & 31.8 & 1.7 & 0.2 & - \\
\hline
\end{tabular}

The TPU soft segments (SS) are defined as the polyol Radia 7285 chains excluding the hexanediol ends chain. The latter are assigned to the formation of the hard segments (HS) in addition to $\mathrm{MDI} / \mathrm{BDO}$ ones. Other polymers were synthesized with a similar chemical composition yet varying the amount of HS, ranging from 8 to $30 \mathrm{wt} \%$ and denoted TPU 8 and TPU 30, respectively. MDI and BDO were provided by Sigma Aldrich Co. and the polyester polyol Radia 7285 was provided by Oleon Co. The synthesis and characteristics of the polymers are presented and discussed in a previous paper[15].

\subsection{Methods}

\subsubsection{Processing of blends}

To prepare the blends, $100 \mathrm{~g}$ of bitumen or oil (naphthenic or paraffinic oil) were placed in a metal pot and heated at $180^{\circ} \mathrm{C}$ in an oven. Granules of TPU were added in the hot bitumen or oil. After 1 hour delay to allow the TPU to soften, the mixture was stirred at 2,500 rpm at $170^{\circ} \mathrm{C}$ for 15 minutes with a Rayneri agitator. The hot blend was then poured on a silicon 
sheet which was placed between two metallic plates and pressed to obtain $2 \mathrm{~mm}$-thick films that were then cooled down to room temperature under flowing air

\subsubsection{Solubility parameters}

Details of the method derived to measure the Hansen' solubility parameters (HSP) of the bitumen, oils, and polymers are provided in a previous paper[15]. HSP were evaluated using HSPiP $^{\circledR}$ software[36] after testing the solubility of the compound in several solvents (choosing an increment value of 1 for soluble situations and a value of 0 for non-soluble situations). About 35-40 mg of compound were placed in a small flask that was filled with 3 $\mathrm{mL}$ of solvent. The mixture was then stirred under ultrasound at room temperature (between 25 and $30^{\circ} \mathrm{C}$ ) for 30 minutes. The solubility power of the considered solvent was evaluated after $24 \mathrm{~h}$. A three dimensional (3D) diagram $\left(\delta_{\mathrm{D}} ; \delta_{\mathrm{P}} ; \delta_{\mathrm{H}}\right)$ of solubility parameters was plotted and a solubility sphere encompassing the good solvents for the considered compound fitted. In addition, the global solubility parameter, $\delta_{\mathrm{TO}}$, and the radius of the solubility sphere, $\mathrm{R}_{0}$, were automatically determined by the software. Finally, the center-to-center distance and the overlapping ratio between the solubility spheres of two components were determined from their HSP values using the distance tool of the software.

\subsubsection{X-ray scattering measurements}

Static small angle X-ray scattering (SAXS) and ultra-small angle X-ray scattering (USAXS) experiments were performed at room temperature with an energy beam of $12.46 \mathrm{keV}$ on the ID2 beamline of the European Synchrotron Radiation Facility (ESRF), Grenoble (France). 
For the SAXS measurements, the sample-detector distance was $1 \mathrm{~m}$ and the exposure time was set at $0.5 \mathrm{~s}$ while for the USAXS investigations, the distance between sample and detector was $10 \mathrm{~m}$ and the exposure time was set at $0.05 \mathrm{~s}$. The SAXS/USAXS twodimensional (2D) patterns of all synthesized TPUs did not show any preferential orientation. For this reason, the $\mathrm{I}=\mathrm{f}(\mathrm{q})$ data presented were obtained from the azimuthal average of the scattering pattern from which all the necessary data corrections have been applied (background scattering subtraction and sample thickness correction). In addition, Kratky plots, I. $\mathrm{q}^{2}=\mathrm{f}(\mathrm{q})$, are presented in order to facilitate the identification of the correlation peaks between HS nodules.

\subsubsection{Rheological behavior}

Rheological properties of TPU were analyzed using an ARES device from TA Instruments at $1 \mathrm{~Hz}$ from $20^{\circ} \mathrm{C}$ to $130^{\circ} \mathrm{C}$ with a plate-plate geometry of $25 \mathrm{~mm}$ of diameter and $2 \mathrm{~mm}$ gap applying a dynamic strain of $\pm 2 \%$.

\subsubsection{Interfacial tension measurements by DDR}

The drop deformation retraction (DDR) method was performed using a Linkam apparatus containing two heating circular quartz plates. A precise scheme and a full description of the device are given in [28] and the authors suggest the reader to refer to it for more details. The sample was put between the plates and sheared at $180^{\circ} \mathrm{C}$ with a shear rate of $0.1 \mathrm{~s}^{-1}$. Only the bottom plate rotates, the top plate being fixed. The microscope positioned at $7.5 \mathrm{~mm}$ from the center allowed to observe the sample through a hole having a diameter of $2.8 \mathrm{~mm}$. The 
software Linkys ${ }^{\circledR}$ permitted the control of the gap, the temperature and the shear rate as well as to record the retraction of the drop from a video camera. A gap between 100 and $150 \mu \mathrm{m}$ was used for the experiment. The pictures obtained were segmented using the Fiji[37] free software to measure the length (L) and width (W) of the drop as a function of time. The method consisted in recording the shape of a deformed drop of a liquid within another one, up to its equilibrium retraction. The interfacial tension $\gamma$ can be estimated from the logarithm of the shape parameter of the drop (D), as a function of time, using the following equations:

$$
\begin{gathered}
D=\frac{L_{0}^{2}-W_{0}^{2}}{L^{2}-W^{2}} \\
\log [D]=\frac{\gamma}{2.303 \times \eta_{m} \times r_{0}} \times \frac{40(p+1)}{(2 p+3)(19 p+16)} t
\end{gathered}
$$

where $p=\frac{\eta_{d}}{\eta_{m}}$ is the zero-shear viscosity ratio between the dispersed phase, $\eta_{d}$, and the matrix, $\eta_{m} ; r_{0}$ the radius of the drop at equilibrium; $L_{O}$ and $W_{O}$ the length and width of the drop at initial time $(\mathrm{t}=0)$ respectively.

The zero shear viscosities values, $\eta$, required for the DDR method were measured at $180^{\circ} \mathrm{C}$ using an ARES rheometer on the bitumen and on a TPU 13 swollen by the naphthenic oil at the exact ratio of aromatics+resins contained according to the Carreau's model[38].

\subsubsection{Florescence microscopy}

Fluorescence microscopy observations were conducted using an optical microscope from Zeiss equipped with a high pressure mercury UV lamp HBO in reflection mode with a twofilter system allowing to analyze specimens under 300-400 and 450-490 nm wavelength ranges. The polymer-modified bitumen samples were broken in liquid nitrogen to analyze 
the through-thickness morphologies. The fluorescence images were segmented using the Fiji software. It is worth noting that the swollen TPU appeared white due to the absorption of aromatic compounds. Thus, its percentage was measured from thresholding and averaged on at least five images. A swelling coefficient was then estimated as the ratio between the average surface fraction of TPU-rich phase measured in the images and the initial weight fraction of the added polymer. Considering the close density values of bitumen and TPU, this coefficient was expected to be equal to one for non-swollen TPU and greater than 1 when swelling occurred.

\section{RESULTS AND DISCUSSION}

\subsection{Compatibility in bitumen-TPU blends}

\subsubsection{Bitumen - TPU}

In our previous paper, Hansen solubility parameters of the TPUs were studied[15]. First, the solubility spheres of all TPUs considered as single macromolecular constituents were determined. In addition, two solubility spheres considered as models for the TPU soft and hard segments, separately, were deduced from a double sphere fitting of the TPU 13 solubility diagram made with $\mathrm{HSPiP}^{\circledR}$ software[36]. These preliminary results are summarized in Table 2. A similar study has been conducted on the 160/220 grade bitumen (BC) which displays a much lower global solubility parameter compared to the TPUs (Table 2). It is worth mentioning that values reported in the literature for various bitumen's solubility parameters are close to those found in this study[16,17]. However, as HSP values of bitumen depend on 
the bitumen nature, slight changes prevailed for instance either a Venezuelan bitumen or another bitumen is used[16,17]. Overall, the TPUs exhibit higher polarities than bitumen and than SBS[19,39] copolymers which are usually combined with bitumen. In order to precisely evaluate the bitumen compatibility with the TPUs, their solubility parameters were compared. First, it is well-established that the closer the solubility parameters between the two compounds, the higher their affinity. As shown in Table 2 and also discussed in another work[15], increasing the hard segment (HS) content of the TPU leads to an increase of its overall solubility parameter. Thus, TPUs with the lowest hard segment content should exhibit the highest compatibility with bitumen.

Table 2. HSP values of bitumen and TPU[40]

\begin{tabular}{lccccc}
\hline Sample & $\delta_{\text {TOT }}$ & $\delta_{\mathrm{D}}$ & $\delta_{\mathrm{P}}$ & $\delta_{\mathrm{H}}$ & Radius $_{0}$ \\
& $(\mathrm{MPa})^{1 / 2}$ & $(\mathrm{MPa})^{1 / 2}$ & $(\mathrm{MPa})^{1 / 2}$ & $(\mathrm{MPa})^{1 / 2}$ & $(\mathrm{MPa})^{1 / 2}$ \\
\hline Bitumen (BC) & $18.4 \pm 0.4$ & $17.9 \pm 0.2$ & $3.1 \pm 0.6$ & $2.3 \pm 0.6$ & 6.8 \\
TPU 8 & $19.7 \pm 0.4$ & $17.9 \pm 0.2$ & $2.7 \pm 0.5$ & $7.7 \pm 0.4$ & 7.3 \\
TPU 13 & $21.2 \pm 0.6$ & $18.1 \pm 0.1$ & $4.9 \pm 1.0$ & $9.8 \pm 0.6$ & 4.4 \\
TPU 30 & $21.4 \pm 0.5$ & $17.5 \pm 0.2$ & $4.7 \pm 0.5$ & $11.3 \pm 0.3$ & 3.7 \\
Soft Segment (SS) & $20.7 \pm 0.9$ & $19.1 \pm 0.6$ & $4.2 \pm 0.9$ & $6.7 \pm 0.4$ & 5.3 \\
Hard segment (HS) & $24.3 \pm 1.5$ & $18.2 \pm 0.5$ & $8.2 \pm 1.7$ & $13.8 \pm 0.9$ & 3.1 \\
\hline
\end{tabular}

To confirm this assumption, the compatibility between bitumen and the TPUs was evaluated using the distance tool of the HSPiP software. Table 3 displays the computed distance between the centers of the solubility spheres of bitumen and the different polymers. At first, the results evidence that the increase of the hard segment content leads to a joint increase in 
the distance between the bitumen and polymer spheres and decrease of their overlapping, thus suggesting a diminished compatibility with the bitumen.

Now, when considering independently both the soft and hard blocks of TPUs, unlike SS, HS show no affinity with bitumen (Figure 1), as no overlapping of their respective solubility spheres exists. This result suggests that only the soft segments are involved for compatibilization in the bitumen.

For low hard segment content, similar distance values are observed in Table 3 between the soft segment and TPU 8 due to their close compositions, the major difference being the addition of a small amount of diisocyanate (4,4'-methylene bis(phenyl isocyanate), MDI) that reacts with the hydroxyl end groups of the polyol. However, the percentage of overlapping between the soft segment and bitumen spheres is two times higher than the one between the TPU 8 and bitumen spheres, confirming a much higher compatibility of the only soft segment with the bitumen (Figure 1a).

A gap in the distance with bitumen sphere is observed from TPU 8 to TPU 13. This one results from a change in the polymer composition and the addition of MDI/BDO hard segments. This change causes a decrease in the polymer compatibility, as attested by the decrease of overlapping of the solubility spheres and the increase of the distance between them.

For high hard segment content, a distance higher than $8 \mathrm{MPa}^{1 / 2}$ between the solubility spheres of TPU 30 (or HS) and bitumen, suggests that these two compounds are indifferently and 
fully incompatible with the bitumen. Nevertheless, the limited yet existing overlap of the solubility spheres involving the TPU 30 testifies that partial compatibility remains with bitumen.

Table 3. Distance of solubility sphere to bitumen BC one and percentage of overlapping of the polymer solubility sphere with that of the bitumen.

\begin{tabular}{lcc}
\hline Material & $\begin{array}{c}\text { Distance } \\
(\mathrm{MPa})^{1 / 2}\end{array}$ & $\begin{array}{c}\text { \% overlap of } \\
\text { TPU sphere }\end{array}$ \\
\hline TPU 8 & 5.4 & 29 \\
TPU 13 & 7.7 & 25 \\
TPU 30 & 9.2 & 6 \\
SS & 5.1 & 62 \\
HS & 12.1 & 0 \\
\hline
\end{tabular}



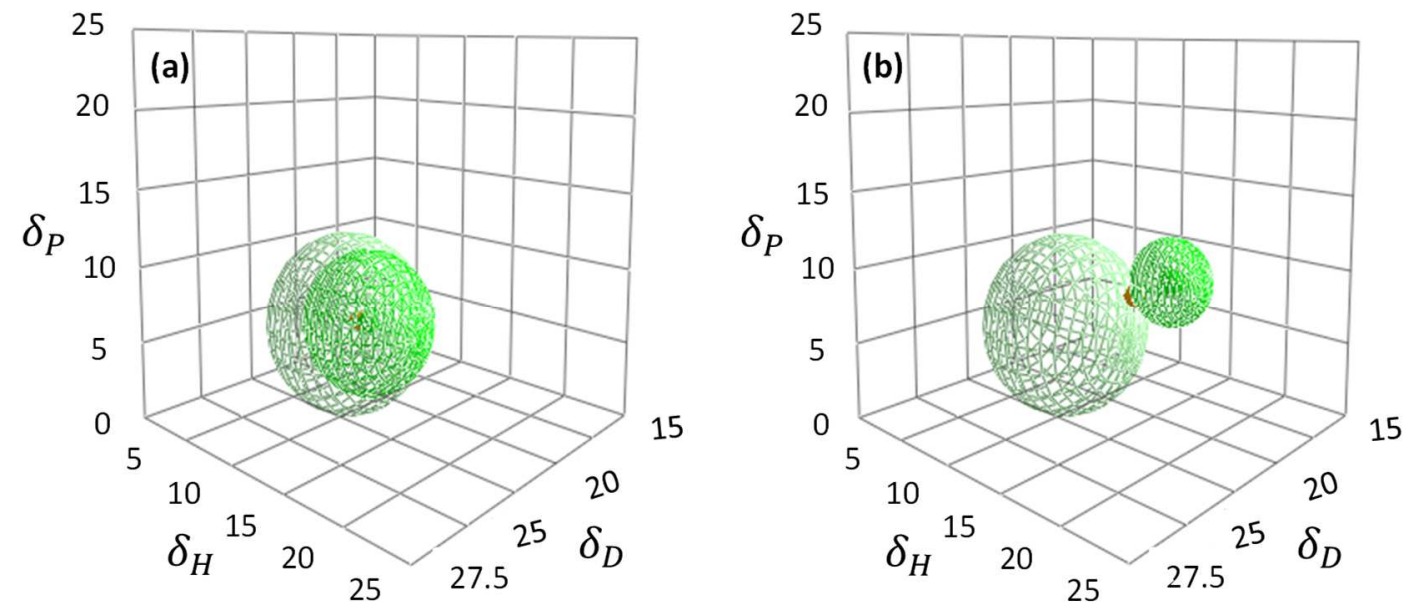

Figure 1: Solubility sphere diagrams $\left(\delta_{\mathrm{D}}\left(\mathrm{MPa}^{1 / 2}\right) ; \delta_{\mathrm{P}}\left(\mathrm{MPa}^{1 / 2}\right) ; \delta_{\mathrm{H}}\left(\mathrm{MPa}^{1 / 2}\right)\right)$ showing comparison of bitumen solubility sphere (light green) with a) soft segment solubility sphere and b) hard segment solubility sphere.

All in all, the distances between the centers of the solubility spheres must be associated with the percentage of overlapping of the spheres in order to have a proper quantification of the compatibility mechanism in TPU-modified bitumen blends. In this study, as MDI/BDO hard segment content increases, the increase in the distance is associated with the decrease in the percentage of overlapping. Besides, differential scanning calorimetry as well wide-angle Xray scattering (WAXS) revealed that the MDI/BDO hard segments can crystallize and remain crystalline in the bitumen-TPU blend with a melting temperature between 180 and $220^{\circ} \mathrm{C}$ (see supporting information Figure S $\mathbf{1}$ and Figure $\mathrm{S}$ 2). This value is similar to those observed in the neat TPU for the hard segments and the presence of diffraction peaks related to crystalline-like structures are clearly evidenced by WAXS. For a blend based on $15 \mathrm{wt} \%$ of TPU 30, the expected melting enthalpy of HS (corrected to the mass of the TPU) is similar 


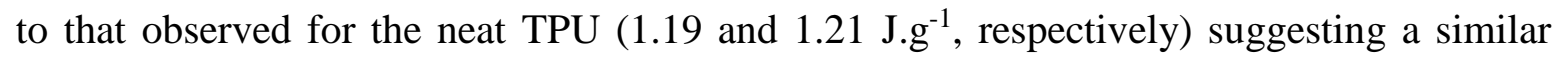
crystallization of the hard segments due to their incompatibility with the bitumen (see supporting information Figure S 1).

Considering the literature devoted to compatibility in polymer-modified bitumen, this result is in agreement with what was reported for SBS-modified bitumen. In such systems, the polystyrene (PS) domains show very poor compatibility with the bitumen phase as evidenced by a partial overlapping between the solubility spheres of bitumen and SBS[17]. Adedeji et al. observed a constant glass transition of $95^{\circ} \mathrm{C}$ for the PS phase when the amount of bitumen increased[41]. Furthermore, considering HSP values of SBS[19,39], it should be highlighted that the distance between centers of the solubility spheres of bitumen and SBS is lower $(<4$ $\left.\mathrm{MPa}^{1 / 2}\right)$ than for bitumen and TPU $\left(>5 \mathrm{MPa}^{1 / 2}\right)$. Thus, SBS should exhibit a higher overall compatibility with the bitumen compared to the TPUs considered in this work (Table 4).

Table 4. HSP value of SBS reported in the literature[19][36] and distance of SBS to bitumen.

\begin{tabular}{|c|c|c|c|c|c|}
\hline Sample & $\begin{array}{c}\delta_{\mathrm{TOT}} \\
(\mathrm{MPa})^{1 / 2}\end{array}$ & $\begin{array}{c}\delta_{\mathrm{D}} \\
(\mathrm{MPa})^{1 / 2}\end{array}$ & $\begin{array}{c}\delta_{\mathrm{P}} \\
(\mathrm{MPa})^{1 / 2}\end{array}$ & $\begin{array}{c}\delta_{\mathrm{H}} \\
(\mathrm{MPa})^{1 / 2}\end{array}$ & $\begin{array}{c}\text { Distance to } \\
\text { bitumen BC } \\
(\mathrm{MPa})^{1 / 2}\end{array}$ \\
\hline SBS [19] & 17.3 & 17.3 & 0.4 & 0 & 2.3 \\
\hline SBS [39] & 17.6 & 17.4 & 1.1 & 2.6 & 3.7 \\
\hline
\end{tabular}

The previous compatibility results (Figure 1 and Table 3) can explain both the resulting morphologies of the bitumen-TPU blends and the associated final mechanical properties. 
Indeed, in a previous work, we showed that increasing the TPU hard segment content led to a decrease in the polymer swelling in the bitumen[42] (see supporting information Figure $S$ 3) which can now be related to the increased incompatibility coming from the hard segment. This non compatibility resulted in a change in the morphology of the blends: more specifically, the TPU-rich phase is seen to transition from a continuous phase at low HS content to a dispersed phase at high HS content [42] (Figure S 3).

\subsubsection{Compatibility of SARA fractions with the TPU}

Bitumen model oils. Bitumen exhibits a complex composition commonly depicted by the well-defined SARA fractions which differ in molecular structures, polarities, and molar masses. In order to clearly identify the interactions of each fraction of the bitumen with the TPU HS and SS blocks, model oils having high contents of aromatics or saturates were considered as well as a model of resins. Hansen solubility parameters of these three models were assessed using HSPiP software and the values are displayed in Table 5. Distances lower than $8 \mathrm{MPa}^{1 / 2}$ were found between these three model materials: $7.3 \mathrm{MPa}^{1 / 2}$ for resinnaphthenic, $7.3 \mathrm{MPa}^{1 / 2}$ for naphthenic-paraffinic, and $6.6 \mathrm{MPa}^{1 / 2}$ for resin-paraffinic, demonstrating their inter-compatibility with bitumen. Table 5 shows that resins display a higher polarity than naphthenic (aromatics) and paraffinic (saturates) oils which is in agreement with the literature and the fact that resins and asphaltenes are known to be the most polar fractions of bitumen. Focusing on the solubility parameter values, the paraffinic oil shows higher polarity than the naphthenic oil. This surprising result is in agreement with 
the reported solubility parameters of bitumens having various compositions, showing that a bitumen with a high saturates content often end up with higher polar and hydrogen bonding components, i.e. higher polarity for the considered bitumen[19].

However, the global solubility parameter, $\delta_{\mathrm{TOT}}$, increases according to the following inequality: paraffinic oil (saturates) < naphthenic oil (aromatics) < resin. This result suggests that aromatics and resins enhance the compatibility potential with the TPU compared to saturates. Furthermore, the overall solubility parameters are in agreement with those reported in literature for this type of fractions[4].

The radii of the solubility spheres are much larger for the model oils than for bitumen as it has a broader and more heterogeneous chemical composition, and are furthermore consistent with values evaluated in the literature for resins[43] and naphthenic oils[44]. Saturates fraction usually displays a solubility parameter from 17.4 to $20 \mathrm{MPa}^{1 / 2}$. In fact, regarding the composition of the paraffinic oil considered in this study, the closest composition, i.e. a bitumen having $70.4 \mathrm{wt} \%$ of saturates and $29.60 \mathrm{wt} \%$ of aromatics reported by Da Silva Ramos et al.[45], displays a value of $17.6 \mathrm{MPa}^{1 / 2}$.

Although the polar and hydrogen bonding components measured for the naphthenic oil are close to values reported in the literature, its dispersive component remains much higher[44]. This difference could be related to the higher ( $>80 \mathrm{wt} \%)$ aromatics content compared to those considered in this paper. For the resins, a relevant comparison is not possible as their solubility parameters are highly dependent on the origin of this fraction. In the present work, the resins are purchased and thus not coming from bitumen. However, literature reports a 
lower polarity for resins extracted by Soxhlet from precipitated asphaltenes with nheptane[43].

Table 5. HSP values of the model oils and resins

\begin{tabular}{lccccc}
\hline Material & $\delta_{\text {TОт }}$ & $\delta_{\mathrm{D}}$ & $\delta_{\mathrm{P}}$ & $\delta_{\mathrm{H}}$ & Radius \\
& $(\mathrm{MPa})^{1 / 2}$ & $(\mathrm{MPa})^{1 / 2}$ & $(\mathrm{MPa})^{1 / 2}$ & $(\mathrm{MPa})^{1 / 2}$ & $(\mathrm{MPa})^{1 / 2}$ \\
\hline Resin & $21.9 \pm 0.6$ & $18.2 \pm 0.4$ & $6.8 \pm 0.4$ & $10.1 \pm 0.4$ & 9.8 \\
Naphthenic oil (N) & $19.9 \pm 0.4$ & $19.0 \pm 0.2$ & $1.1 \pm 0.3$ & $5.9 \pm 0.5$ & 10.2 \\
Paraffinic oil (P) & $18.2 \pm 1.0$ & $15.7 \pm 0.8$ & $2.7 \pm 0.6$ & $8.7 \pm 0.5$ & 9.8 \\
\hline
\end{tabular}

The oils were then mixed with various TPU 13 contents. Exudation of the paraffinic oil is observed for the highest content of polymer $(50 \mathrm{wt} \%)$ while the naphthenic oil always leads to homogeneous blends with the TPU. This phenomenon could be associated to a poor affinity between the paraffinic oil and TPU 13.

In order to confirm the considered approach based on Hansen solubility parameters, only the distance between the solubility spheres centers of the model oils and the TPU segments was measured. In fact, the solubility sphere of the hard segments is included in those of the model oils due to the large radius of the latter ones (Table 6). It can be noticed that aromatics exhibit the highest compatibility with the soft phase, i.e. the lowest distance between solubility sphere centers. The saturates exhibit a much larger distance, i.e. a lower compatibility with soft segments, whereas the resins display an intermediate behavior. However, resins show the best compatibility with MDI/BDO hard segments whereas both aromatics and saturates remain incompatible with the hard segments as evidenced by a distance greater than $8 \mathrm{MPa}^{1 / 2}$. 
Based on these results and bitumen $\mathrm{BC}$ composition, it is assumed that aromatics along with resins are responsible for the efficient compatibility of the bitumen with the TPU considered in this study, as aromatics constitute the major fraction of bitumen BC (62 wt \%). According to these conclusions, one can explain that for a bitumen BC/TPU 13 blend, the aromatics fraction should contribute to fully swell the soft segment of the TPU-rich phase, while the resins fraction should swell the whole TPU-rich phase, i.e. both soft and hard segments.

Table 6. Distances between the solubility sphere centers of the model oils and TPU blocks

\begin{tabular}{lcc}
\hline & $\begin{array}{c}\text { Distance to SS } \\
(\mathrm{MPa})^{1 / 2}\end{array}$ & $\begin{array}{c}\text { Distance to HS } \\
(\mathrm{MPa})^{1 / 2}\end{array}$ \\
\hline Saturates (P) & 7.2 & 9.1 \\
Aromatics (N) & 3.2 & 10.8 \\
Resins & 4.1 & 4.6 \\
\hline
\end{tabular}

\section{Interfacial tension measurements.}

As previously reported, resins display a higher affinity for the whole TPU. However, for the bitumen considered in this study, the resins content is much lower than the aromatics one, i.e. leading to the precise identification of the role of resins in bitumen compatibility. Thus, two different bitumens (BA and BC) with different SARA compositions were considered to prepare blends with $30 \mathrm{wt} \%$ of TPU 13. Both resulting blends have a morphology composed of a continuous TPU rich-phase with dispersed bitumen-rich microparticles whereas blends based on a low TPU content display a reverse morphology, i.e. a bitumen continuous phase 
with TPU-rich particles. Interfacial tension measurements at $180^{\circ} \mathrm{C}$ using the drop deformation retraction (DDR) method described earlier were made on the two blends.

Figure $2 \mathrm{a}$ shows the profile of the deformed bitumen drop with initial length $\left(L_{0}\right)$ and width $\left(W_{0}\right)$ and which evolutions with time (see SI Figure $S 4$ ) will be considered to calculate the shape parameter, D, i.e. $D(t)=\frac{L_{0}^{2}-W_{0}^{2}}{L(t)^{2}-W(t)^{2}}$. The plot of the logarithm of the shape parameter vs. time (Figure $2 \mathrm{~b}$ and $\mathrm{c}$ ) leads to a linear polynomial behavior for which the slope is related to the interfacial tension according to equation (4) in method section. The two plots evidence the fact that the retraction times of the droplets clearly differ. Indeed, the droplet retracts much faster for blends made from bitumen BC, i.e. within a hundred of seconds, compared to the blends made from bitumen BA, where more than three hundred seconds are needed to retract to an equilibrium state.

This different behavior can be related to the large variations of interfacial tensions encountered in the two blends. Intuitively, a rapid retraction suggests that the affinity of the embedded droplets with its neighboring phase is not favorable whereas a slow retraction advocates for a strong affinity, i.e. expected interactions between components. Thus, a lower interfacial tension is expected between the bitumen BA and TPU compared to the bitumen BC and TPU. Noticeably, bitumen BA has a higher resin content than bitumen BC (23.8 wt\% vs. $15.5 \mathrm{wt} \%$ respectively), suggesting that larger amounts of resins lead to better compatibility. 
(a) $\mathrm{t}=0 \mathrm{~s}$
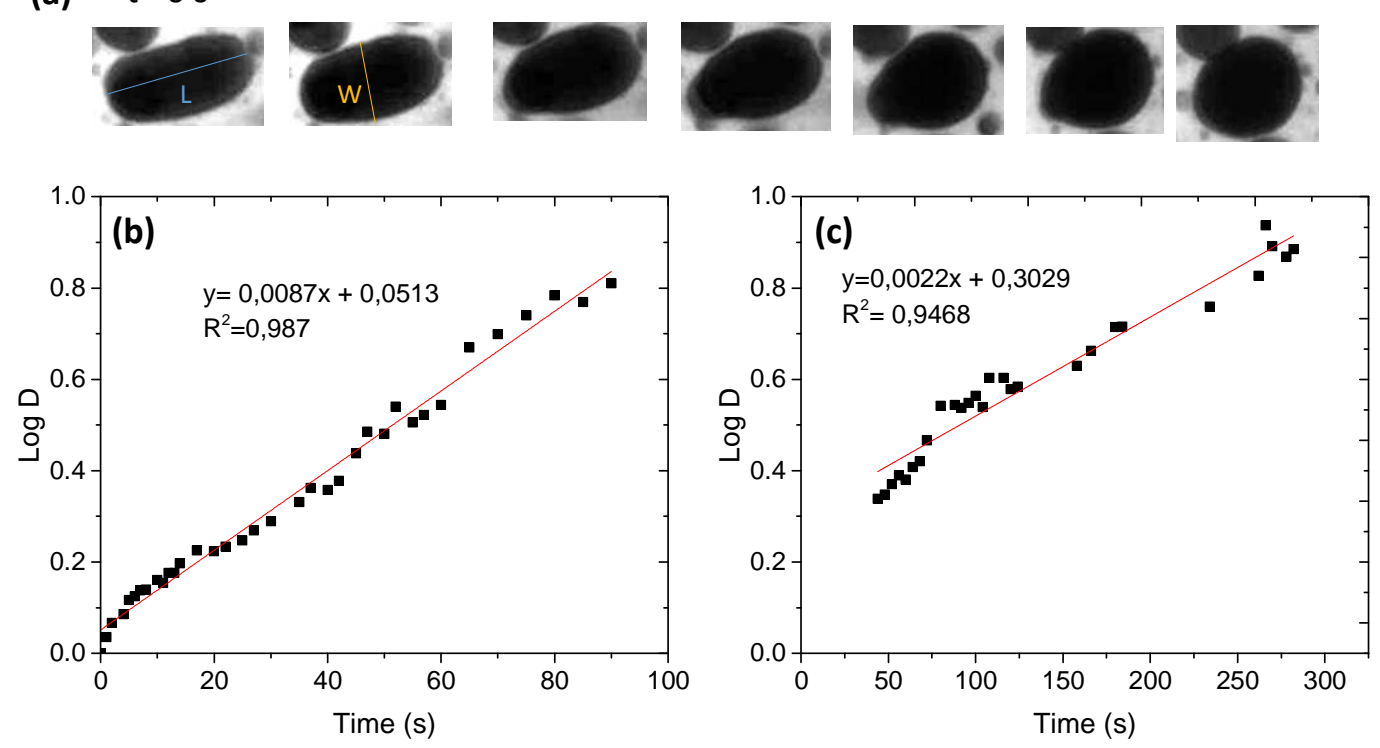

Figure 2. a) Shape evolution of a bitumen BC droplet in TPU. b) Logarithm of the droplet shape factor of bitumen BC embedded in TPU with time; c) Logarithm of the shape parameter of the droplet of bitumen BA in TPUwith time.

The zero shear viscosities of the two blends having a bitumen continuous phase, i.e. a bitumen matrix, were measured allowing for the analysis of the viscosity ratio $p$, defined as $p=\frac{\eta_{d}}{\eta_{m}}$. Table 7 provides the radius $r_{0}$ of the droplets at equilibrium, the matrix viscosity $\eta_{m}$ and the ratio used to access the interfacial tension $\gamma$ according to Equation (4). As expected, interfacial tension within $10^{-6} \mathrm{~N} \cdot \mathrm{m}^{-1}$ are determined for bitumen/TPU blends. These values are in agreement with the literature for bitumen blends, either with polyethylene using the drop deformation retraction method, or SBS-modification followed by rheology[29,31].

Interfacial tension in blends made from a bitumen based on the lowest resin content, i.e. 10.8 $\mathrm{wt} \%$ in $\mathrm{BC}$ bitumen, is more than ten times higher than in the blend containing a high resin 
content, i.e. $16.7 \mathrm{wt} \%$ in bitumen BA-based blend. Thus, resins demonstrate their compatibilizing role in bitumen/TPU blend.

Table 7. interfacial tension measured at $180^{\circ} \mathrm{C}$ and initial parameters considered for

\begin{tabular}{lcc} 
& \multicolumn{2}{c}{ calculation. } \\
\hline & BC 30 & BA 30 \\
& wt\% TPU & wt\% TPU \\
\hline $\mathrm{r}_{0}(\mu \mathrm{m})$ & 44.1 & 18.9 \\
$\eta_{\mathrm{m}}($ Pa.s $)$ & 0.71 & 0.63 \\
$\mathrm{p}$ & 0.66 & 0.70 \\
$\gamma\left(\mu \mathrm{N} . \mathrm{m}^{-1}\right)$ & $1.77 \pm 0.16$ & $0.14 \pm 0.03$ \\
\hline
\end{tabular}

\subsection{TPU swelling in bitumen}

Based on the aforementioned results, one can consider the analysis of the microstructure of the swollen TPU-rich phase. X-ray scattering was used on model blends made of naphthenic oil and TPU 13. Small angle X-ray scattering (SAXS) spectra of the TPU 13 and TPUnaphthenic oil blends with different oil contents are shown in Figure 3Erreur ! Source du renvoi introuvable.. The analysis of the neat TPU, i.e. before blending with the model oil has already revealed the existence of several scattering peaks. The first one, observed for a scattering vector $q_{1}$ corresponding to a dimension of $7 \mathrm{~nm}$ according to Bragg law, is related to the hard domains. A second correlation peak at $q_{2}$ gives the interdomain distance $\left(d_{2}\right)$ of $13 \mathrm{~nm}$ (see Table 8 and sketch in Figure 4 a). 

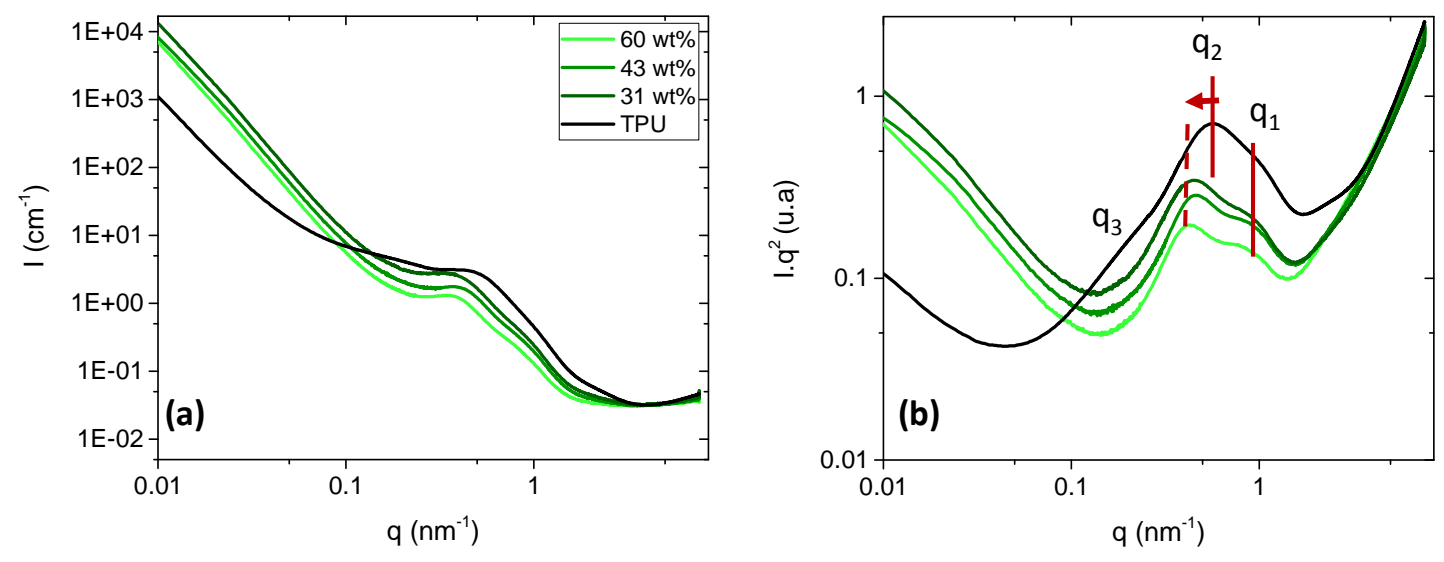

Figure 3. SAXS profiles of TPU 13 and TPU 13 based blends with various weight contents of naphthenic oil a) $I=f(q)$ and b) Kratky' plot (I.q $\left.{ }^{2}\right)=f(q)$.

Table 8. Correlation distances obtained from SAXS analyses for naphthenic oil/TPU 13 blends.

\begin{tabular}{lccc}
\hline Oil content & $\mathrm{d}_{1}(\mathrm{~nm})$ & $\mathrm{d}_{2}(\mathrm{~nm})$ & $\mathrm{d}_{3}(\mathrm{~nm})$ \\
\hline $0 \mathrm{wt} \%$ (TPU) & 7.0 & 11.0 & 31.4 \\
$31 \mathrm{wt} \%$ & 7.8 & 13.9 & \\
$43 \mathrm{wt} \%$ & 7.9 & 13.6 & \\
$60 \mathrm{wt} \%$ & 8.2 & 14.9 & \\
\hline
\end{tabular}

A third scattering peak, denoted as $q_{3}$, gives the distance between larger aggregates of hard domains, i.e. $31.4 \mathrm{~nm}[15]$. The TPU and naphthenic oil blends display a microstructure where the hard segment-rich nanodomains remain well separated from the soft phase as the scattering peaks at $q_{1}$ and $q_{2}$ are still present. Yet, the addition of supplementary naphthenic oil from 31 to $60 \mathrm{wt} \%$ leads to an increase in the interdomain distance $d_{2}$ (Figure 3 and Table 8) associated with the swelling of the soft segments separating the hard domains and results from the good affinity of the soft segments with aromatics (Table 6 and Figure 4 b). 
One can notice that in this case, due to the higher swelling of the soft segments, the SAXS $q_{3}$ correlation peak is shifted to the extent where it is no longer experimentally visible

Regarding the hard segment-rich domains dimension, a slight increase could be noted with the addition of oil. For $60 \mathrm{wt} \%$ of oil, the increase of both domains dimension and correlation distance suggest that the hard domains are also slightly swollen by some oil components. Indeed, the increase in the hard segment-rich domain dimension leads to an increase in the interdomain distance. In fact, the naphthenic oil used to prepare these blends contains a small amount of resins which can swell both hard domains and soft segments (Table 6), thus implying an increase of both $d_{1}$ and $d_{2}$. As a result, the characteristics of the blend having the highest oil content confirms the affinity predicted by the Hansen solubility parameters regarding both the aromatics and the resins related interactions. Furthermore, it has been previously established from the DSC and WAXS analyses presented in SI (Figures S 1 and S 2), that HS crystalline characteristics (amount and morphology) remain unchanged both in the pure TPU 30 and in the blend with bitumen BC and $15 \mathrm{wt} \%$ of TPU 30. Consequently, at this stage, the swelling of HS by resins seem to essentially occur within the amorphous rigid domains as illustrated in Figure $4 \mathrm{~b}$.

To sum up, the differences in compatibility between SARA fractions of the bitumen and blocks of the TPU justify the partial swelling of the polymer in the bitumen/TPU blend . The final morphology of the blend is made of two phases, a bituminous one rich in asphaltene 
and saturate fractions and a TPU-rich one swollen by resin and aromatic fractions. The microstructure of the latter is made of hard domains partially swollen by resins, with its crystalline phase remaining unchanged, and dispersed in a soft continuous matrix swelled by aromatic and resin fractions.

All in all, both the resin content and the amount of amorphous vs. crystalline hard segments must be first order parameters to control the final morphologies and consequently the mechanical behavior of the bitumen-polymer blends.

Recently, literature reported similar conclusions on SBS-modified asphalt studied using small angle neutron scattering (SANS). The authors showed that the microstructure of the swollen SBS in bitumen remained the same as that of the neat SBS polymer[46], specifically that the lamellar nanostructure of SBS persisted in the bitumen-SBS blends. In addition, increasing the temperature to $110^{\circ} \mathrm{C}$ led to an increase of the correlation distance of the SBS phase, revealing its dispersion in the blend and its swelling by the low molar mass fractions of bitumen. Ho et al.[13] also reported an increase of interdomain spacing with maltenes concentration on SEBS-bitumen blends from SAXS analyses. 

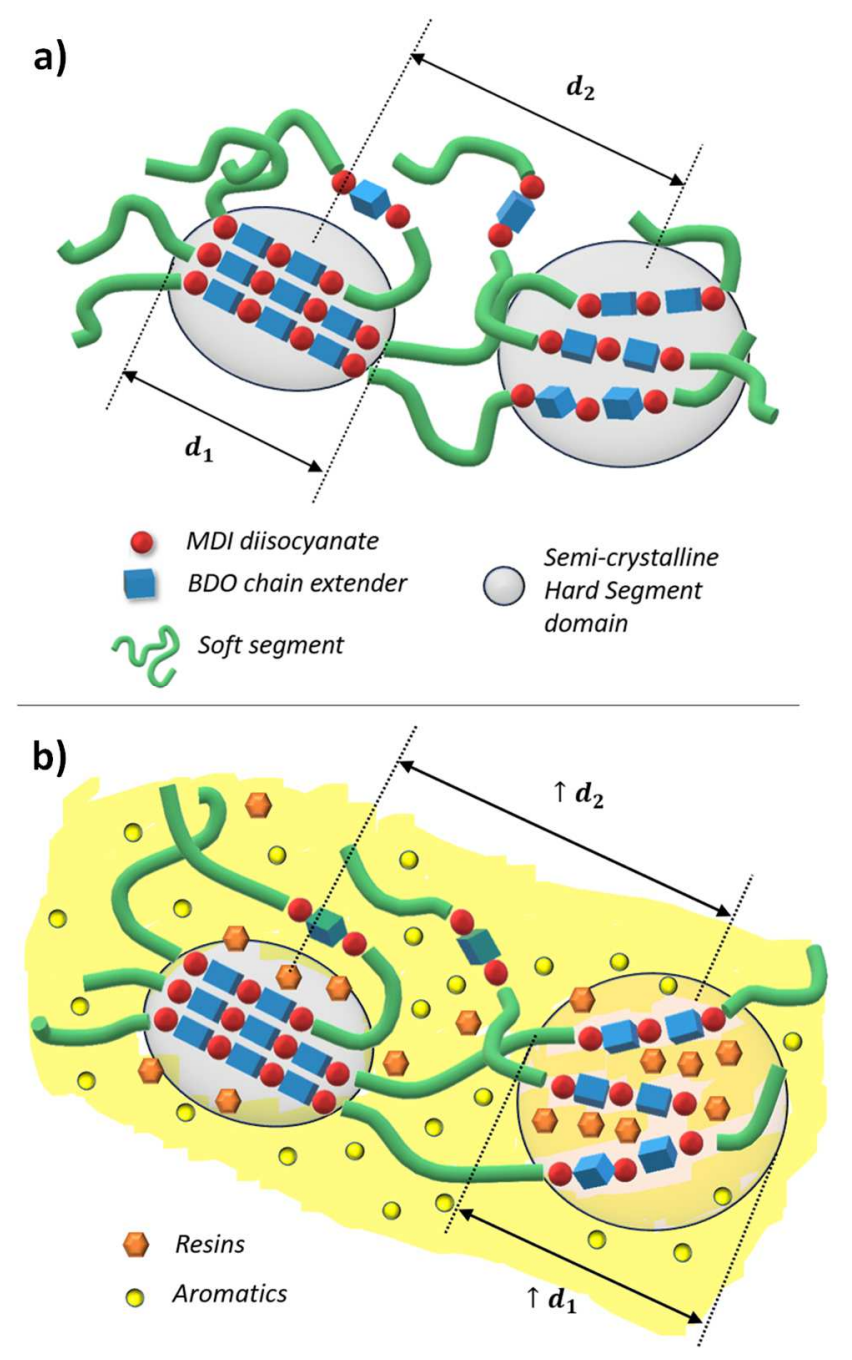

Figure 4. Sketch representing the microstructure of the TPU a) before and b) after swelling by bitumen fractions.

Three bitumen with different SARA compositions were used to prepare blends containing 23 wt\% of TPU 13. For this polymer content, the morphology consists in a continuous swollen TPU-rich phase and a dispersed bitumen rich-phase as shown in Figure 5. The swelling of the TPU-rich phase remains the same whatever the bitumen considered, with a swelling coefficient close to 2.6 as estimated by image analysis. 

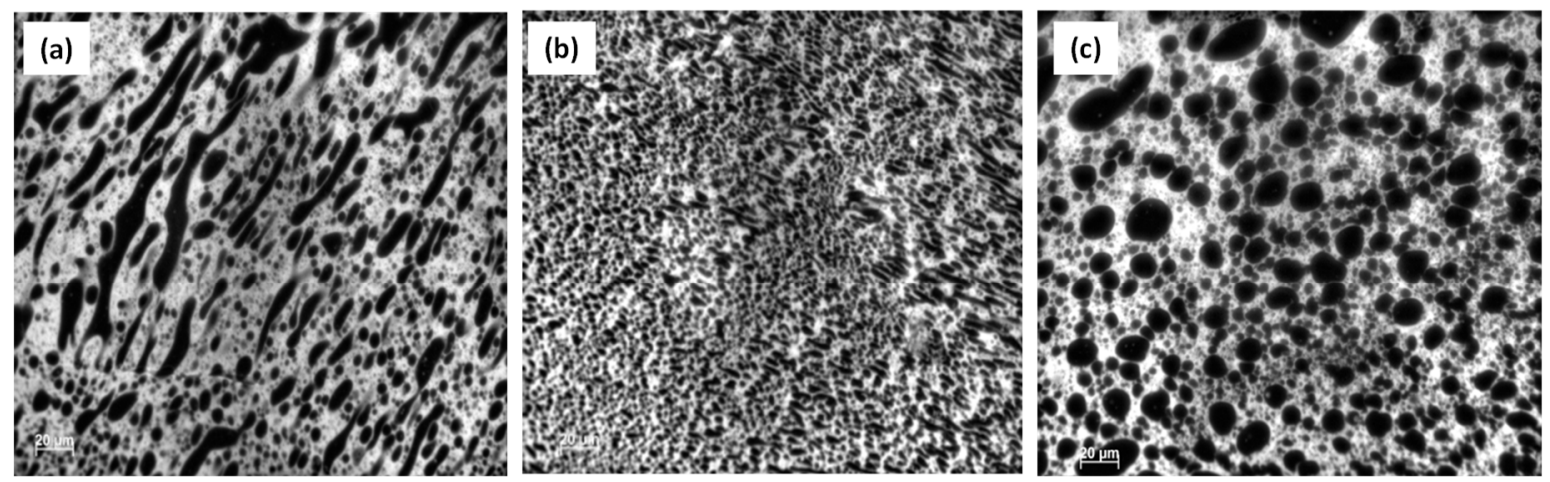

$-20 \mu \mathrm{m}$

Figure 5: Fluorescence optical microscopy images of blend containing $23 \mathrm{wt} \%$ of TPU 13 prepared from a) bitumen $\mathrm{BA}, \mathrm{b})$ bitumen $\mathrm{BB}$ and c) bitumen $\mathrm{BC}$.

\section{Mechanical properties.}

It is well known that the partial swelling of the polymer phase in bitumen-polymer blends is a key factor to enhance its mechanical properties compared to those of the neat bitumen[42].

Figure 6 show rheological behaviors of the three blends.

Whatever the bitumen, the continuous TPU-rich phase governs the whole mechanical properties of the blend, and allows to display a thermoplastic elastomeric behavior, i.e. $\tan \delta$ $<1$ and the existence of a rubbery plateau due to the nanostructuration of the TPU-rich phase.

As shown previously on oil/TPU blends, this phase contains hard segment-rich domains acting as physical crosslinking nodes and reinforcing nanofillers that can disassemble at high temperature and thus permit the flow of the material (Figure 6).

Nevertheless, the rheological properties are seen to depend on the bitumen composition (Figure 6). Indeed, both storage modulus and temperature at which the material flows decrease from the blend made with bitumen $\mathrm{BC}$ to that based on bitumen $\mathrm{BA}$. 
Studies performed on SBS-modified bitumen[2] and reported in the literature have shown that the higher the amount of aromatics in the bitumen, the higher the compatibility with the polymer. This phenomenon is associated with an increase in the elastic response (storage modulus) at low frequency and a higher swollen polymer content. Another work described the compatibility of bitumen using Gaestel's index defined as the ratio of (asphaltenes+saturates) to (aromatics+resins) contents[1]. The authors reported that for a low Gaestel's index, a longer storage stability for a SBS-modified bitumen could be associated to the existence of a homogeneous morphology of the blends over a wide range of temperature, whereas for blends having a high Gaestel's index, a heterogeneous morphology was observed[1].

Applying the same approach, the bitumen BA leads to a Gaestel's index of 0.267, bitumen BB to 0.296 and bitumen BC to 0.290 . Consequently, the bitumen BA is expected to exhibit the better compatibility in agreement with the interfacial tension analyses reported previously (Table 7). However, similar values for the other two bitumens suggest that this index is not relevant enough to distinguish the varying compatibility of two bitumens with close compositions. Thus, according to our knowledge on the role of the fractions responsible for the TPU swelling, i.e. aromatics and resins, it can be assumed that aromatics cannot be responsible for the observed behavior. Indeed, aromatics display a good affinity only with the soft phase of the TPU and the only swelling of this soft phase cannot explain the observed softening ( $\mathrm{E}$ ' one order of magnitude lower with BA bitumen compared to $\mathrm{BC}$ one). 
As a consequence, the swelling of the amorphous phase of the hard segment-rich domains by resins has to be considered. On the one hand, resin-HS interactions can hinder the association of HS (apart from crystallization), i.e. the physical crosslinking of the elastically active SS network, provoking the decrease of the storage modulus and an increase of the loss factor as observed in Figure 6. On the other hand, one can assume that the intrinsic modulus of the hard domains and their thermal stability are also lowered as a consequence of the HS - resin compatibility. Consequently, the modulus of the TPU-rich phase and its flowing temperature decrease.

It thus appears that the resin fraction having a good affinity for the hard domains could be responsible for the observed changes (Figure 6). Indeed, the higher the resin content, the higher the swelling of the hard domains and the lower the storage modulus and flowing temperature of the TPU-bitumen blend. The lower Gaestel's index for bitumen BA is in agreement with its higher resin's content which contributes to a higher TPU/bitumen compatibility. The resulting higher TPU swelling is also in agreement with the lower interfacial tension between TPU and bitumen for blends having a high resins content (Figure 2 and Table 7). In our previous study we highlighted the importance of TPU composition, i.e. hard segment's content, on the bitumen/TPU blend viscoelastic properties[42]. In addition to that, the present work evidences that bitumen composition plays also a key role in the resulting mechanical properties of TPU-bitumen blends. Thus, relationships between compatibility, i.e. SARA bitumen and TPU compositions, and mechanical properties could be evidenced. 

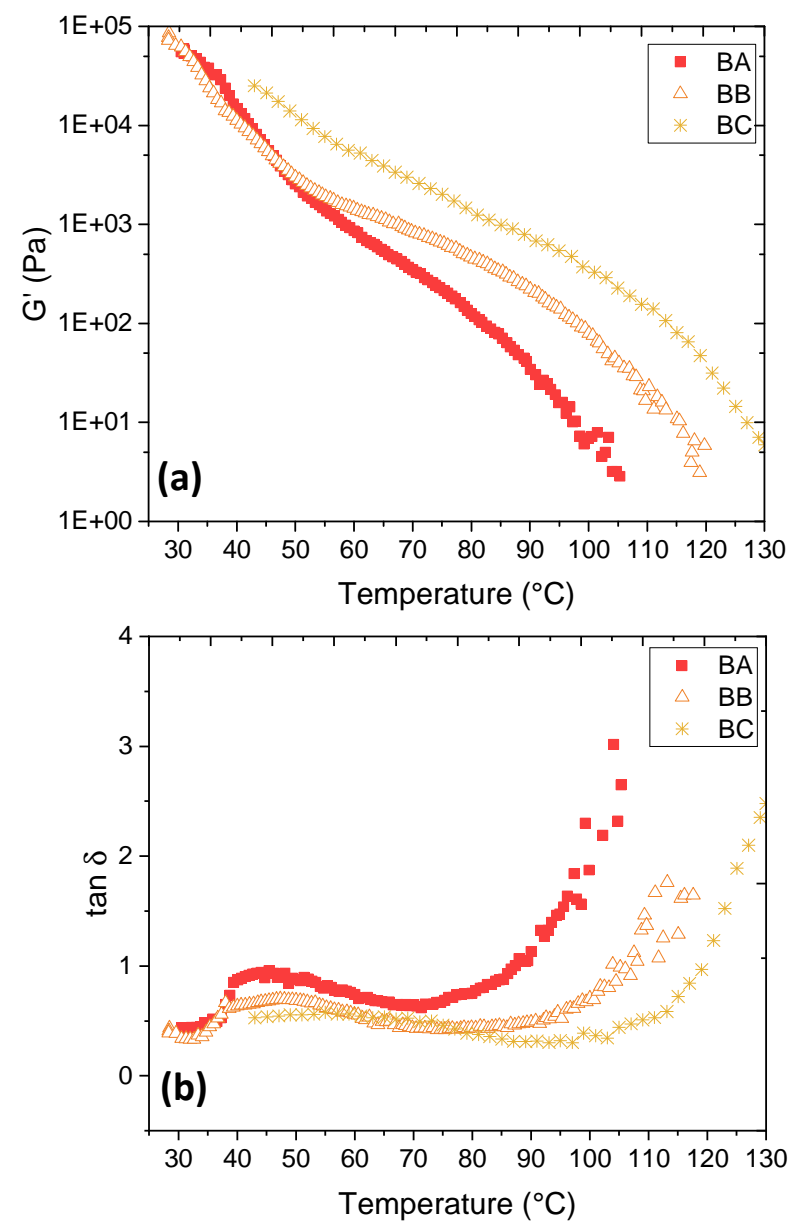

Figure 6. Storage modulus and loss factor of 3 TPU-bitumen blends based on $23 \mathrm{wt} \%$ TPU 13 as a function of temperature at $1 \mathrm{~Hz}$.

\section{Conclusions}

This study proposes a general understanding of the compatibility mechanisms in bitumenTPU blends from Hansen's solubility parameters combined with experimental interfacial tension measurements. HSP have been estimated for bitumen and models of aromatics, resins, and saturates fractions in order to relate the compatibility of the SARA fractions with 
the two blocks of the TPU, i.e. hard and soft segments. From HSPs, the compatibility of bitumen with the TPU has been precisely described with use of both the distance between the solubility spheres centers and their degree of overlapping. Furthermore, model fractions highlighted the respective roles of aromatics and resins in changing the affinity between the various components of bitumen-TPU blends. HSP-based approach shows that bitumen displays higher interactions with the soft segments of the TPU. Enhanced interactions cannot be ensured from those between the bitumen and the MDI/BDO hard segments which are found to be low and only interaction with the resins, which display favorable interactions with both soft and hard segments, could be responsible. Precisely, resins act as compatibilizers in bitumen-TPU blends, as they allow additional swelling of the TPU, leading to a low interfacial tension at the processing temperature.

Therefore, the partial swelling of the TPU in bitumen, explained by the limited compatibility of bitumen fractions with the hard segments, maintains the nanostructuration of the swollen TPU-rich phase, i.e. its thermoplastic elastomeric characteristic. Indeed, slightly swollen hard segments remain semi-crystalline, with the crystalline phase maintaining the thermoplastic elastomer-like mechanical behavior to the TPU-bitumen blend, highlighted by the existence of an extended rubbery plateau at high temperature whose modulus level and flowing temperature increase as the resin content decreases. 


\section{Acknowledgements}

The authors express their thanks to Prof. René Fulchiron (IMP, Univ. Lyon1) for granting access to the Linkam device and helpful discussions. Renaud Rinaldi is highly acknowledged for is careful reading of the manuscript.

\section{References}

[1] J. Oliver, K.Y. Khoo, K. Waldron, The effect of SBS morphology on field performance and test results, Road Mater. Pavement Des. 13 (2012) 104-127. https://doi.org/10.1080/14680629.2011.644113.

[2] G.D. Airey, Rheological properties of styrene butadiene styrene polymer modified road bitumens, Fuel. 82 (2003) 1709-1719. https://doi.org/10.1016/S00162361(03)00146-7.

[3] M. Liang, P. Liang, W. Fan, C. Qian, X. Xin, J. Shi, G. Nan, Thermo-rheological behavior and compatibility of modified asphalt with various styrene-butadiene structures in SBS copolymers, Mater. Des. 88 (2015) 177-185. https://doi.org/10.1016/j.matdes.2015.09.002.

[4] F. Dong, W. Zhao, Y. Zhang, J. Wei, W. Fan, Y. Yu, Z. Wang, Influence of SBS and asphalt on SBS dispersion and the performance of modified asphalt, Constr. Build. Mater. 62 (2014) 1-7. https://doi.org/10.1016/j.conbuildmat.2014.03.018.

[5] M. Liang, S. Ren, W. Fan, X. Xin, J. Shi, H. Luo, Rheological property and stability of polymer modified asphalt: Effect of various vinyl-acetate structures in EVA 
copolymers, Constr. Build. Mater. $137 \quad$ (2017) 367-380. https://doi.org/10.1016/j.conbuildmat.2017.01.123.

[6] A. Schaur, S. Unterberger, R. Lackner, Impact of molecular structure of SBS on thermomechanical properties of polymer modi fi ed bitumen, Eur. Polym. J. 96 (2017) 256-265. https://doi.org/10.1016/j.eurpolymj.2017.09.017.

[7] V. V Ginzburg, J. Bicerano, C.P. Christenson, A.K. Schrock, A.Z. Patashinski, Theoretical Modeling of the relationship between Young's modulus and formulation variables for segmented polyurethanes, J. Polym. Sci. Part B Polym. Phys. 45 (2007) 2123-2135. https://doi.org/10.1002/polb.

[8] L. Leibler, Theory of microphase separation in block copolymers, Macromolecules. 13 (1980) 1602-1617. https://doi.org/10.1021/ma60078a047.

[9] E. Manias, L.A. Utracki, Thermodynamics of polymer blends, Springer, Dordrecht, 2014. https://doi.org/10.1007/978-94-007-6064-6_4.

[10] J.T. Koberstein, T.P. Russell, Simultaneous SAXS-DSC study of multiple endothermic behavior in polyether-based polyurethane block copolymers, Macromolecules. 19 (1986) 714-720.

[11] J.F. Masson, P. Collins, G. Robertson, J.R. Woods, J. Margeson, Thermodynamics, phase diagrams , and stability of bitumen - polymer blends, Energy and Fuels. 17 (2003) 714-724.

[12] R. Varma, H. Takeichi, J.E. Hall, Y.F. Ozawa, T. Kyu, Miscibility studies on blends of Kraton block copolymer and asphalt, Polymer (Guildf). 43 (2002) 4667-4671. 
https://doi.org/10.1016/S0032-3861(02)00303-8.

[13] R.-M. Ho, A. Adedeji, D.W. Giles, D.A. Hajduk, C.W. Macosko, F.S. Bates, Microstructure of triblock copolymers in asphalt oligomers, J. Polym. Sci. Part B Polym. Phys. 35 (1997) 2857-2877.

[14] Y. Brion, B. Brulé, Etude des mélanges bitumes-polymères. Composition-structurepropriétés, Rapp. Des Lab. (1986) 7-121.

[15] R. Gallu, F. Méchin, F. Dalmas, J.-F. Gérard, R. Perrin, F. Loup, On the use of solubility parameters to investigate phase separation-morphology-mechanical behavior relationships of TPU, Polymer (Guildf). $207 \quad$ (2020) 122882. https://doi.org/https://doi.org/10.1016/j.polymer.2020.122882.

[16] C.M. Hansen, Hansen solubility parameters: a user's handbook, Second Edition, Second Edi, Taylor \& Francis Group, Boca Raton, 2007.

[17] P. Redelius, Bitumen solubility model using hansen solubility parameter, Energy and Fuels. 18 (2004) 1087-1092. https://doi.org/10.1021/ef0400058.

[18] J. Zhu, R. Balieu, H. Wang, The use of solubility parameters and free energy theory for phase behaviour of polymer-modified bitumen : a review, Road Mater. Pavement Des. (2019) 1-22. https://doi.org/10.1080/14680629.2019.1645725.

[19] T. Wang, X. Huang, Y. Zhang, Application of Hansen solubility parameters to predict compatibility of SBS-modified bitumen, J. Mater. Civ. Eng. 22 (2010) 773-778. https://doi.org/10.1061/(ASCE)MT.1943-5533.0000011.

[20] A. Sreeram, Z. Leng, R. Hajj, A. Bhasin, Characterization of compatibility between 
aged and unaged binders in bituminous mixtures through an extended HSP model of solubility, Fuel. 254 (2019) 115578. https://doi.org/10.1016/j.fuel.2019.05.161.

[21] D.J. David, T.F. Sincock, Estimation of miscibility of polymer blends using the solubility parameter concept, Polymer (Guildf). 33 (1992) 4505-4514. https://doi.org/10.1016/0032-3861(92)90406-M.

[22] P. Furtwengler, R. Matadi Boumbimba, A. Sarbu, L. Avérous, Novel Rigid Polyisocyanurate Foams from Synthesized Biobased Polyester Polyol with Enhanced Properties, ACS Sustain. Chem. Eng. $6 \quad$ (2018) 6577-6589. https://doi.org/10.1021/acssuschemeng.8b00380.

[23] C. Zhang, M.R. Kessler, Bio-based polyurethane foam made from compatible blends of vegetable-oil-based polyol and petroleum-based polyol, ACS Sustain. Chem. Eng. 3 (2015) 743-749. https://doi.org/10.1021/acssuschemeng.5b00049.

[24] N.R. Demarquette, A.M.C. De Souza, G. Palmer, P.H.P. Macaubas, Comparison between five experimental methods to evaluate interfacial tension between molten polymers, Polym. Eng. Sci. 43 (2003) 670-683.

[25] P. Xing, M. Bousmina, D. Rodrigue, M.R. Kamal, Critical experimental comparison between five techniques for the determination of interfacial tension in polymer blends : Model system of polystyrene / polyamide-6, Macromolecules. 33 (2000) 8020-8034.

[26] G. Palmer, N.R. Demarquette, Evaluation of imbedded fiber retraction phenomenological models for determining interfacial tension between molten polymers, $\quad$ Polymer $\quad$ (Guildf). $\quad 46 \quad$ (2005) 8169-8177. 
https://doi.org/10.1016/j.polymer.2005.06.047.

[27] Y. Son, J.T. Yoon, Measurement of interfacial tension by a deformed drop method, Polymer (Guildf). 42 (2001) 7209-7213.

[28] R. Al-Itry, K. Lamnawar, A. Maazouz, Rheological, morphological, and interfacial properties of compatibilized PLA/PBAT blends, Rheol. Acta. 53 (2014) 501-517. https://doi.org/10.1007/s00397-014-0774-2.

[29] D. Lesueur, J.G. Gérard, P. Claudy, J. Létoffé, D. Martin, J.-P. Planche, Polymer modified asphalts as viscoelastic emulsions, J. Rheol. (N. Y. N. Y). 42 (1998). https://doi.org/10.1122/1.550918.

[30] J.F. Palierne, Linear rheology of viscoelastic emulsions with interfacial tension, Rheol. Acta. 29 (1990) 204-214. https://doi.org/10.1007/BF01331356.

[31] C. Roman, M. García-Morales, Optical microscopy visualization on droplet relaxation and breakup in a LDPE modified bitumen, Mater. Des. 107 (2016) 353-360. https://doi.org/10.1016/j.matdes.2016.06.055.

[32] R. Gallu, F. Méchin, F. Dalmas, J.F. Gérard, R. Perrin, F. Loup, Rheologymorphology relationships of new polymer-modified bitumen based on thermoplastic polyurethanes (TPU), Constr. Build. Mater. 259 (2020) 1-10. https://doi.org/10.1016/j.conbuildmat.2020.120404.

[33] E. Delebecq, J.P. Pascault, B. Boutevin, F. Ganachaud, On the versatility of urethane/urea bonds: Reversibility, blocked isocyanate, and non-isocyanate polyurethane, Chem. Rev. 113 (2013) 80-118. https://doi.org/10.1021/cr300195n. 
[34] C. Prisacariu, Polyurethane elastomers from morphology to mechanical aspects, Springer, 2011.

[35] M.F. Sonnenschein, Polyurethanes sciences, technology, markets, and trends, Hoboken, John Wiley \& Sons, Inc, New Jersey, USA, 2015.

[36] S. Abbott, C.M. Hansen, H. Yamamoto, Hansen solubility parameters in practice complete with eBook, software and data 5th edition, 2013.

[37] J. Schindelin, I. Arganda-Carreras, E. Frise, V. Kaynig, M. Longair, T. Pietzsch, S. Preibisch, C. Rueden, S. Saalfeld, B. Schmid, J. Tinevez, D. White, V. Hartenstein, K. Eliceiri, P. Tomancak, A. Cardona, Fiji: an open-source platform for biological-image analysis. Nature methods 9(7), (2012) 676-682. https://doi.org/10.1038/nmeth.2019.

[38] P.J. Carreau, Rheological equations from molecular network theories., Trans. Soc. Rheol. 16 (1972) 99-127. https://doi.org/10.1122/1.549276.

[39] G. Ovejero, M.D. Romero, E. Díez, I. Díaz, Thermodynamic interactions of three SBS (styrene-butadiene-styrene) triblock copolymers with different solvents, by means of intrinsic viscosity measurements, Eur. Polym. J. 46 (2010) 2261-2268. https://doi.org/10.1016/j.eurpolymj.2010.10.016.

[40] R. Gallu, F. Méchin, F. Dalmas, J.-F. Gérard, R. Perrin, F. Loup, On the use of solubility parameters to investigate phase separation-morphology-mechanical behavior relationships in TPUs - under soumission, Polymer (Guildf). (2020).

[41] A. Adedeji, T. Grunfelder, F.S. Bates, C.W. Macosko, M. Stroup-Gardiner, D.E. Newcomb, Asphalt modified by SBS triblock copolymer: Structures and properties, 
Polym. Eng. Sci. 36 (1996) 1707-1723.

[42] R. Gallu, F. Méchin, F. Dalmas, J.-F. Gérard, R. Perrin, F. Loup, Rheologymorphology relationships of new polymer-modified bitumen based on thermoplastic polyurethanes (TPU), Constr. Build. Mater. $259 \quad$ (2020) 120404. https://doi.org/https://doi.org/10.1016/j.conbuildmat.2020.120404.

[43] S. Acevedo, A. Castro, E. Vasquez, F. Marcano, M.A. Ranaudo, Investigation of physical chemistry properties of asphaltenes using solubility parameters of asphaltenes and their fractions A1 and A2, Energy and Fuels. 24 (2010) 5921-5933. https://doi.org/10.1021/ef1005786.

[44] M. Levin, P. Redelius, Determination of three-dimensional solubility parameters and solubility spheres for naphthenic mineral oils, Energy and Fuels. 22 (2008) 33953401.

[45] A.C. Da Silva Ramos, M. Pinheiro Rolemberg, L.G. Moraes de Moura, E.L. Zilio, M. de F. Pereira dos Santos, G. Gonzalez, Determination of solubility parameters of oils and prediction of oil compatibility, J. Pet. Sci. Eng. 102 (2013) 36-40. https://doi.org/10.1016/j.petrol.2013.01.008.

[46] L. Shan, R. Xie, N.J. Wagner, H. He, Y. Liu, Microstructure of neat and SBS modified asphalt binder by small-angle neutron scattering, Fuel. 253 (2019) 1589-1596. https://doi.org/10.1016/j.fuel.2019.05.087. 


\section{SUPPORTING INFORMATION}

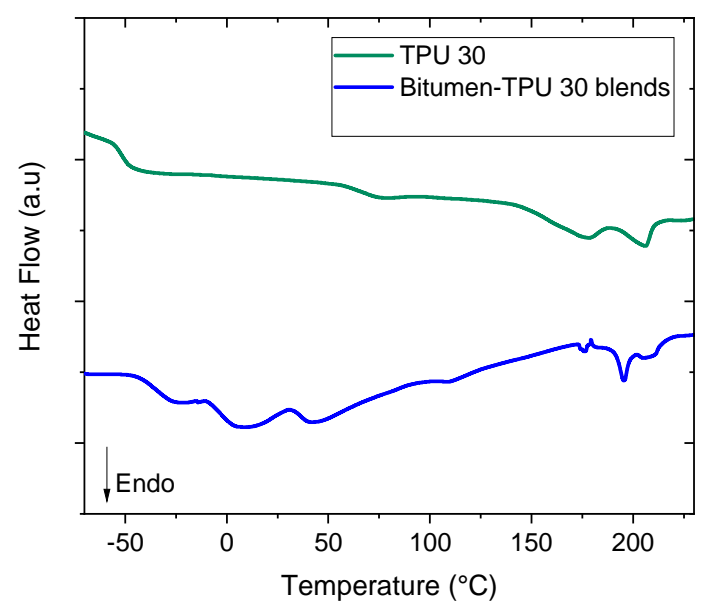

Figure S 1. Differential scanning calorimetry thermograms of TPU 30 and bitumen-TPU blend containing $15 \mathrm{wt} \%$ of TPU 30 (heating rate: $10^{\circ} \mathrm{C} \cdot \mathrm{min}^{-1}$ ).

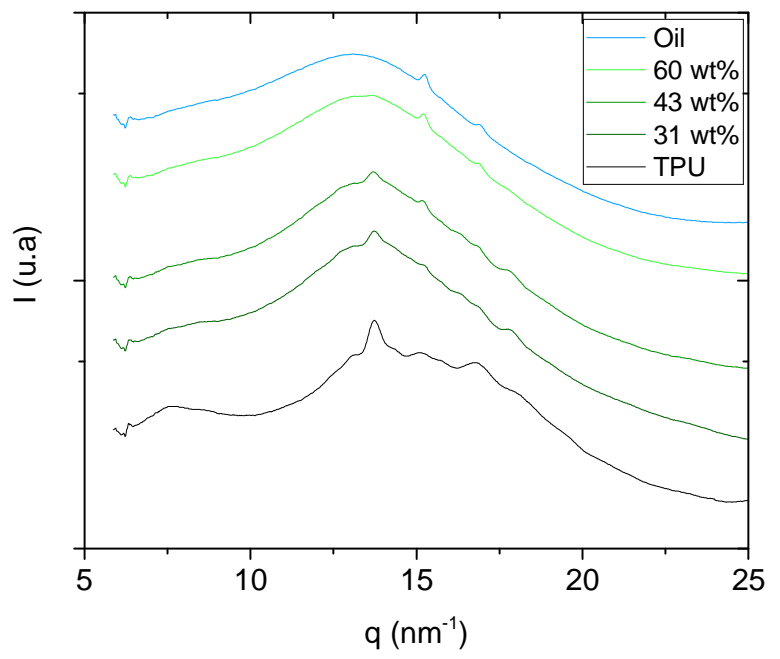

Figure S 2. Wide angle X-ray diffraction patterns of the naphthenic oil, TPU 30, and TPU 30 swollen by various content of naphthenic oil. 

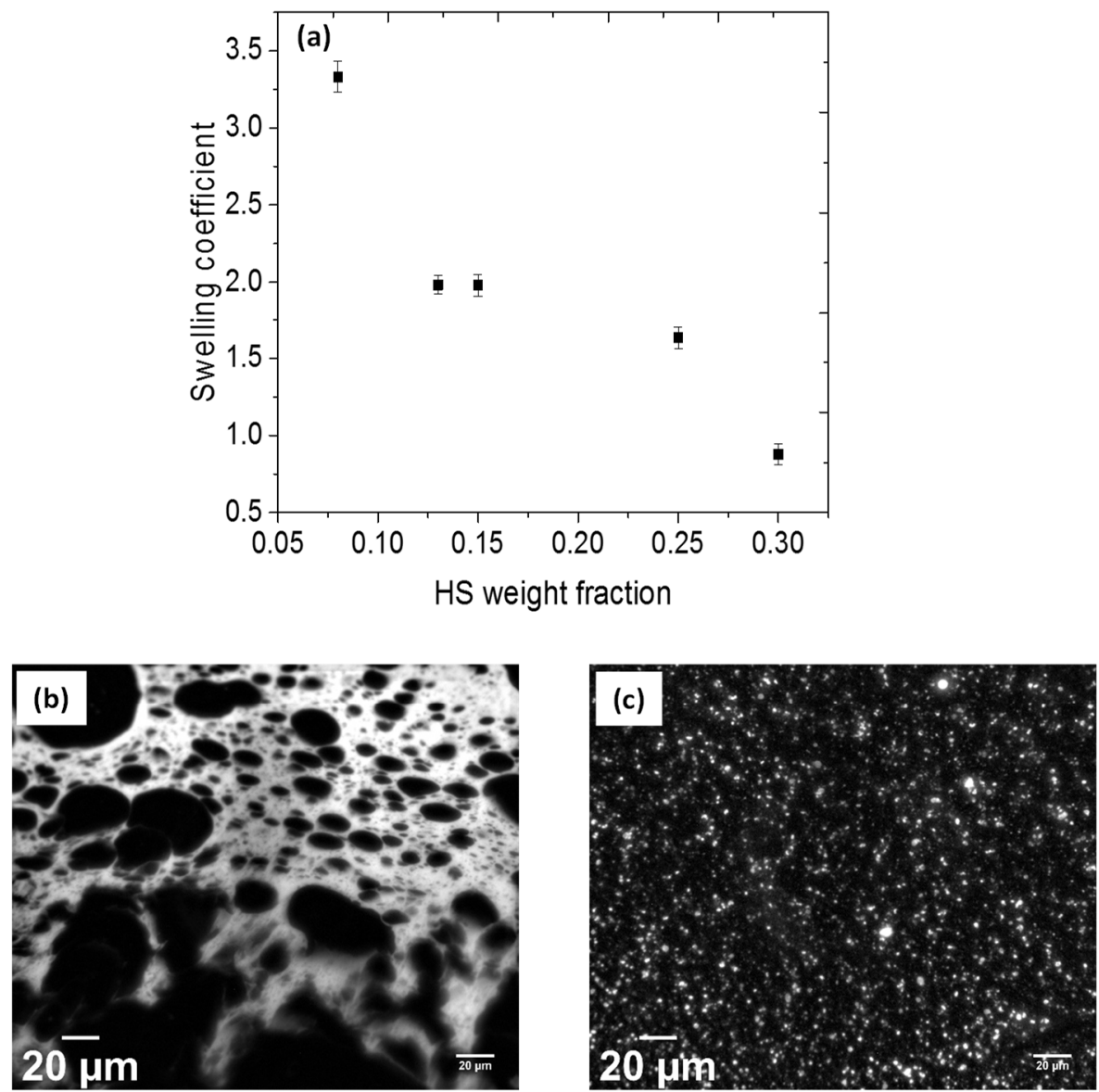

Figure S 3. a) Swelling of the TPU in bitumen as a function of HS content; Fluorescence optical microscopy image of blend containing $15 \mathrm{wt} \%$ of TPU 8; b) Fluorescence optical microscopy image of blend containing $15 \mathrm{wt} \%$ of TPU 30.
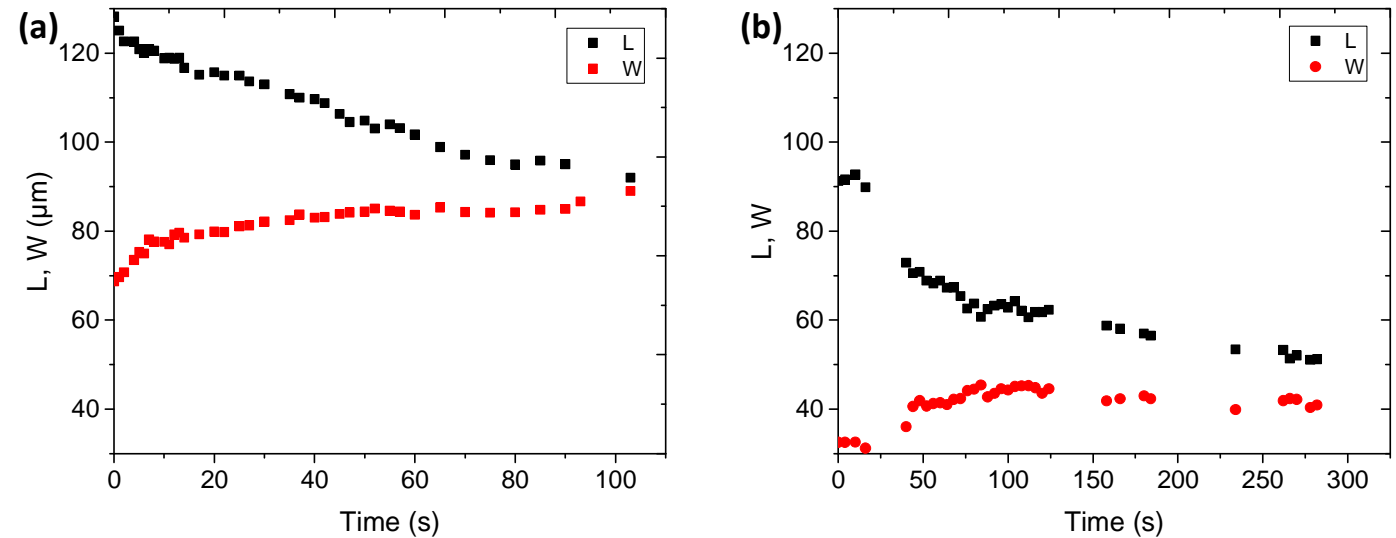

Figure S 4. Shape parameter, length (L), and width (W) for bitumen droplets embedded in TPU-rich continuous phase: a) bitumen BC and b) bitumen BA. 